\title{
UMIDADE EM EDIFICAÇÕES: CONHECER PARA COMBATER ${ }^{1}$
}

\author{
Yuri Mariano Carvalho ${ }^{2}$ \\ Vivian Gemiliano Pinto
}

\begin{abstract}
RESUMO
A água é uma das maiores problemáticas dentro do escopo de estudo da Engenharia Civil, visto originar cerca de $80 \%$ de todas as patologias construtivas e ainda ser capaz de causar danos à saúde dos ocupantes da edificação. Mesmo estando presente tanto no ambiente externo (na forma de chuva e águas subterrâneas) quanto no ambiente interno da habitação (no ato de cozinhar e tomar banho, por exemplo), em muitas obras o projeto de impermeabilização é negligenciado, permitindo que a umidade se manifeste por variadas formas. Nesse contexto, buscou-se classificar a água quanto sua forma de manifestação a partir do cruzamento dos dados expostos por autores clássicos e contemporâneos, além de listar indícios de sua ação deteriorante, formas de tratamento e medidas preventivas a serem tomadas contra a umidade. O propósito almejado neste artigo é o de que as informações apresentadas possam auxiliar na identificação e reparo de patologias relativas à umidade e, também, destacar a importância da realização de projetos de impermeabilização, levando-os a serem incluídos no conjunto de projetos mínimos necessários a execução de uma obra.
\end{abstract}

Palavras-chave: Umidade. Patologia das construções. Manutenção de edifícios. Impermeabilização.

\section{INTRODUÇÃO}

Desde os primórdios da civilização, o ser humano vem desenvolvendo maneiras e aplicando novos materiais em suas obras para minimizar os efeitos debilitantes da água sobre as edificações. A umidade, constante tópico de interesse nos estudos da área da construção civil (AGYEKUM et al., 2013; FRANZONI; BANDINI; GRAZIANI, 2014), é a responsável pela maior parte das patologias construtivas, como apontado pelo Conselho Internacional de Pesquisa e Inovação na Construção Conseil International du Bâtiment (CIB) (CIB W86, 1993) e em outros estudos na área (AGYEKUM et al., 2013). Tal fato deve-se tanto aos danos causados à estrutura da edificação e à consequente diminuição do conforto higrotérmico quanto à proliferação de microrganismos nocivos à saúde humana (ANILLA et al., 2017;

\footnotetext{
${ }^{1}$ Como citar este artigo: CARVALHO, Yuri Mariano. PINTO, Vivian Gemiliano. Umidade em edificações: conhecer para combater. ForScience: revista científica do IFMG, Formiga, v. 6, n. 3, e00476, jul./dez. 2018.
}

\footnotetext{
${ }^{2}$ Autor para correspondência: Yuri Mariano Carvalho: yuri.mariano@engenharia.ufjf.br
} 
KHARSEH et al., 2017; RIPPER, 1984), o que a levou a ser estudada por órgãos de saúde internacionais, como a Academia Nacional de Medicina dos Estados Unidos Institute of Medicine (IOM) e a Organização Mundial da Saúde World Health Organization (WHO) (IOM, 2004; WHO, 2009).

No entanto, a ausência de uma metodologia que seja aceita em escala mundial para o tratamento de patologias relativas a umidades (assim como para o tratamento de outras patologias em geral), acaba por deixar sem resolução uma grande parcela de problemas construtivos.

Sob a ótica de Lichtenstein (1986), tal realidade decorre do fato de que instituições e profissionais da área da construção civil optam por valer-se da própria experiência e habilidades adquiridas na prática em detrimento de uma base científica. A evolução das sociedades e, consequentemente, a maior complexidade das construções e materiais na atualidade, exigem a formulação de tratamentos mais efetivos para as mais variadas patologias e que o acesso a essas informações seja amplo e de universal aplicação (CIB W86, 1993). Como apresentado por Tutikian e Pacheco (2013), os três pilares para o tratamento patológico em edificações são: a inspeção, o diagnóstico e o prognóstico, os quais convergem para a terapia a ser adotada. Mesmo que não seja costume entre os brasileiros o ato de conservar preventivamente os bens edificados, como apontado pelo Instituto de Patrimônio Histórico e Artístico Nacional (IPHAN) (KLÜPPEL; SANTANA, 2000), é necessário estimular esse hábito na sociedade, visando a redução nos custos com reformas desnecessárias.

Visto isso, buscou-se nesse trabalho apresentar um referencial teórico sobre os tipos de umidade que podem acometer uma edificação, atentando para formas de ocorrência, elementos agravantes e possíveis tratamentos, além de ponderar sobre a melhor alternativa a ser seguida para evitar a ocorrência de anomalias advindas da água em uma construção.

\section{METODOLOGIA}

O presente estudo baseou-se no levantamento teórico de informações em livros técnicos e artigos sobre as patologias oriundas da ação de umidade, classificando-as quanto sua forma de manifestação e discorrendo sobre suas especificidades, além de trazer informações sobre termos técnicos na área da patologia das construções. A partir disso, foram listadas sugestões de práticas a serem adotadas para cada caso de combate tanto à degradação visível quanto às suas possíveis fontes de origem.

ForSci.: r. cient. IFMG campus Formiga, Formiga, v. 6, n. 3, e00476, jul./dez. 2018. 


\section{UMIDADE EM EDIFICAÇÕES}

A água se comporta como o maior agente degradante para edificações. Segundo estudos realizados na Noruega, a umidade e problemas relativos à água correspondem a 76\% das patologias que acometem uma construção (FREITAS, 2013). A Organização Mundial da Saúde, por sua vez, coloca que entre $75 \%$ e $80 \%$ das patologias que acometem o invólucro de uma edificação tem suas origens na umidade (WHO, 2009).

Visto isso, o vocábulo umidade, no âmbito da construção civil, acaba por ser utilizado em inúmeros casos como forma de definição para problemas relativos à água em seus mais variados estados, formas de manifestação e danos causados à edificação. Segundo a IOM, os termos mais utilizados como sinônimos para umidade são "condensação", "umidade de construção", "umidade visível", "manchas úmidas", "água estagnada" e "problemas de umidade" (IOM, 2004).

A umidade, ou qualquer outro termo utilizado para expressá-la, é empregada como indicador para uma ampla gama de sinais relativos a danos causados pela ação da água tanto no plano espacial quanto no de severidade das patologias (IOM, 2004). Espacialmente, poderse-iam listar as manifestações visíveis da umidade, como manchas de água em paredes, condensações em janelas e desenvolvimento microbiano, as quais cada uma apresentam determinada gravidade na agressão à estrutura da edificação.

A prevenção e o combate à umidade, como apresentado pela Corporação de Desenvolvimento Tecnológico Corporación de Desarrollo Tecnológico (CDT) da Câmara Chilena de Construção, além de atenuarem a aparição de manchas e mofos, esmorecem o desenvolvimento de enfermidades relativas a microrganismos ou à própria umidade que possam acometer os usuários da edificação (CDT, 2012; WHO, 2009).

\subsection{Conceitos prévios sobre a água}

Além de ser o composto químico mais abundante sobre a superfície terrestre, a água pode manifestar-se sob três estados físicos diferentes (sólido, líquido e gasoso) devido a variações de temperatura e pressão, fato que a torna um elemento com alta capacidade de penetrar nos mais variados materiais (RODRIGUEZ, 2004). Ao infiltrar-se sob a forma líquida em materiais porosos, tais quais o concreto, a água pode provar-se altamente danosa caso congele, já que ela diminui a densidade ao solidificar, expandindo (CDT, 2012). É no estado gasoso, no entanto, que a água apresenta maior capacidade de penetrar e se alojar nos 
poros de um corpo sólido (IOM, 2004) em um fenômeno chamado "absorção" (DEMO, 2017), que pode ser físico (através de forças de interação de Van Der Waals) ou químico (as moléculas de vapor de água são absorvidas a partir de reações químicas).

Devido ao $\mathrm{pH}$ neutro e de sua estrutura altamente polar, a água pode atuar como solvente e transportar uma miríade de substâncias que podem levá-la a apresentar características ácidas ( $\mathrm{pH}<7)$, básicas ou alcalinas $(\mathrm{pH}>7)$ (RODRIGUEZ, 2004) e atuar como um corrosivo sobre os elementos construtivos. Isso é visível quando esquadrias de metal são expostas à umidade, permitindo, assim, o contato entre o metal e os sais transportados pela água, o que leva à corrosão do primeiro através de reações eletroquímicas (CDT, 2012; DEMO, 2017).

Mesmo abundante na natureza e essencial para a manutenção da vida na Terra, a água comporta-se como um elemento prejudicial às construções devido às propriedades expostas anteriormente e que conferem alta agressividade frente aos componentes da edificação (RODRIGUEZ, 2004); a absorção de água por elementos construtivos pode levar a variância volumétrica, a mudanças em propriedades mecânicas e ao surgimento de forças capazes de deformar e distorcer os materiais utilizados (SON; YUEN, 1993).

\section{TIPOS DE UMIDADE}

Sendo considerada um elemento negativo e gerador de patologias construtivas, a umidade é um elemento natural e está presente em menores ou maiores níveis ao redor de uma edificação (SON; YUEN, 1993), havendo, inclusive, fontes internas de umidade geradas pelo uso doméstico ou por processos industriais (IOM, 2004; SON; YUEN, 1993; STRAUBE, 2002).

A umidade só se converte em problema quando acaba por manifestar-se de forma indesejada e em proporção muito acima da tida como aceitável (CDT, 2012). Em grande quantidade, ela pode, por exemplo, estabelecer condições propícias para degradações, físicas, químicas e biológicas dos elementos construtivos (FRANZONI; BANDINI; GRAZIANI, 2014).

A partir de dados gerados em trabalhos acadêmicos e científicos na área das patologias das construções e do cruzamento destes com aqueles gerados por organizações como a CDT (2012), a WHO (2009) e o IOM (2004), é possível formular definições quanto aos tipos de umidade com relação à sua manifestação na obra. 
Adotou-se no presente trabalho, portanto, as seguintes categorias de classificação para umidade: (i) umidade acidental; (ii) umidade ascensional; (iii) umidade de condensação; (iv) umidade da construção; e (v) umidade de precipitação. Vale ressaltar, no entanto, que as manifestações de umidade geralmente ocorrem de maneira associada. Por exemplo, a subida de água por capilaridade em fundações, além de trazer sais capazes de gerar danos à estrutura da edificação e facilitar a infiltração de água de chuva, pode diminuir a temperatura das paredes e a resistência térmica, levando ao aparecimento de condensações pela superfície. Logo, o mais comum é que um tipo de umidade leve ao outro, provocando manifestações simultâneas capazes de dificultar o processo de diagnóstico (ANILLA et al., 2017; HENRIQUES, 1994). As fontes causadoras de umidade encontram-se relacionadas na FIG. 1, que segue.

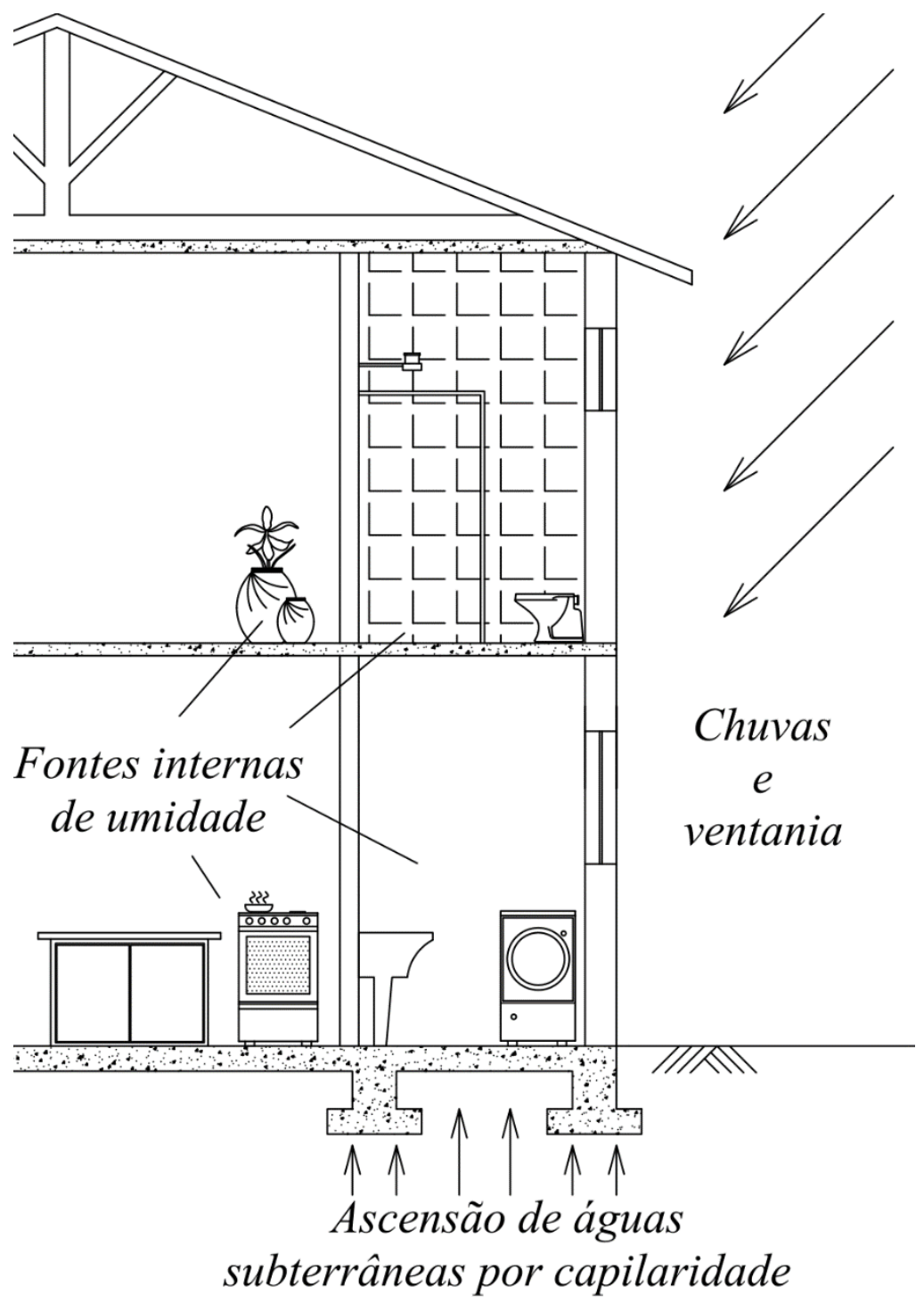

Figura 1 - Croqui esquemático com potenciais fontes de umidade em edificações Fonte: Dos autores. 


\subsection{Umidade acidental}

A água que é trazida intencionalmente para o interior das edificações é confinada por um longo trajeto de tubos, tendo seu destino final em torneiras, chuveiros, lava-pratos, lavadoras de roupa e aparelhos de ventilação. Quando qualquer elemento nesse caminho apresenta algum problema, seja por falta de manutenção, design mal elaborado ou por descuido dos indivíduos que usufruem da edificação, a água torna-se passiva de vazar e de levar à ocorrência de problemas de umidade na edificação (CDT, 2012; IOM, 2004; RODRIGUEZ, 2004; STRAUBE, 2002; WHO, 2009)

Juntas de tubulação soldadas incorretamente, encaixes metálicos desprotegidos contra a corrosão, calhas mal projetadas e bloqueadas por folhas e pisos sem inclinação em direção aos ralos (IOM, 2004; SON; YUEN, 1993) são exemplos clássicos de agentes de umidade acidental. O uso que indivíduos fazem da água, como ao tomar banho, regar plantas e cozinhar, também elevam a umidade do ar no interior da edificação quando esta possui ventilação inadequada, visto não haver dispersão do excesso para o ambiente externo, podendo gerar problemas substanciais à construção (KHARSEH et al., 2017; IOM, 2004).

Portanto, não é difícil de se identificar e tratar esse tipo de umidade através de manutenção adequada; para evitá-la, no entanto, maior atenção deve ser dada ao projeto e à execução deste, visto a aleatoriedade da manifestação da umidade (CDT, 2012).

\subsection{Umidade ascensional}

A sucção capilar é uma das quatro formas de transporte da umidade do exterior para o interior de uma edificação, sendo as outras três a infiltração de líquidos, a difusão de vapor de água e o movimento de ar (LSTIBUREK; CARMODY, 1991). A capilaridade atua levando a umidade através de pequenos poros no material pela qual se alastra, indo contra a ação da gravidade. Isso ocorre devido à tensão superficial da molécula de água e à pressão hidrostática, que permiti-lhe mover-se tanto vertical quando horizontalmente por materiais com altos índices de porosidade (FREITAS; GUIMARÃES, 2014; PROSKIW, 2007; RODRIGUEZ, 2004; SON; YUEN, 1993). O avanço da água através da capilaridade é facilitado quando ocorre a evaporação dos líquidos acumulados nas camadas superiores do material pelo qual ela ascende, o que retroalimenta o processo (FREITAS; GUIMARÃES, 2014; RODRIGUEZ, 2004). 
Em materiais com vácuos intersticiais muito grandes, como cascalho e areia grossa (LSTIBUREK; CARMODY, 1991), ou com poros irrisórios, como mantas de telhado de alcatrão (IOM, 2004), ou desprovidos de poros, como vidro, metal e a maioria dos plásticos (IOM, 2004; LSTIBUREK; CARMODY, 1991; PROSKIW, 2007) não existe a ação da capilaridade.

Geralmente, a umidade ascensional aflige o primeiro piso das edificações devido a impermeabilizações mal executadas em fundações, paredes e pisos (CDT, 2012; SON; YUEN, 1993) e a má escolha dos materiais para compor tais elementos (LSTIBUREK; CARMODY, 1991). É facilmente identificada por vegetação parasitária e manchas escuras em muros e paredes, as quais raramente umedecem a mão ao contato, devido ao efeito da evaporação, exceto em ambientes fechados (CDT, 2012; HENRIQUES, 1994; RODRIGUES; SOBRINHO JÚNIOR; LIMA, 2016); também é indicada pelo surgimento de eflorescências e criptoflorescências (sais cristalizados no exterior e no interior dos elementos construtivos, respectivamente, devido aos sais trazidos pela água ao aflorar do solo e sua posterior evaporação) (CDT, 2012; HENRIQUES, 1994; KHARSEH et al., 2017). Aspectos importantes de sua perniciosidade residem na possível presença de sulfatos na água, os quais ao cristalizar podem gerar tensões e desagregação dos materiais da edificação devido ao aumento de até $40 \%$ do volume original (RODRIGUEZ, 2004) e em sua capacidade de acelerar processos de deterioração, como ataques físico-químicos, ação biológica e erosão por força dos ventos (FRANZONI; BANDINI; GRAZIANI, 2014).

Como todo solo em que se constrói está sujeito a certo grau de umidade, o qual varia devido à proximidade com lençóis freáticos, à presença de água de chuva no terreno e à drenagens empreendidas equivocadamente (CDT, 2012; RODRIGUEZ, 2004; SON; YUEN, 1993), é impossível evitá-la completamente, sendo costumeiramente controlada através de barreiras físico-químicas, aplicação de forros ou ventilação das paredes acometidas por anomalias (FREITAS; GUIMARÃES, 2014).

\subsection{Umidade de condensação}

A umidade por condensação consiste na formação de água líquida a partir do contato de vapor de água $80 \%$ a $85 \%$ dos problemas de umidade tem sua origem na condensação e na umidade produzida pelo próprio homem (AGYEKUM et al., 2013; RYAN, 2002).

Para que ocorra a umidade por condensação, é necessário que a temperatura no ambiente para um dado volume de vapor de água decaia para uma temperatura abaixo do 
ponto de orvalho, o qual indica a temperatura máxima em que o ambiente se satura com vapor de água, ou que o ambiente torne-se saturado por não mais admitir vapor de água a uma temperatura constante (CDT, 2012; SON; YUEN, 1993). Percebe-se, portanto, que tanto temperatura quanto pressão colaboram para a manifestação desse tipo de umidade.

As duas formas de manifestação da umidade por condensação são a superficial e a intersticial. Comum em cômodos expostos a períodos de altas temperaturas e alta umidade relativa do ar, como cozinhas, lavabos e banheiros. A condensação superficial tende a ocorrer em janelas, paredes e tubulações de água fria, visto que os períodos de calor são relativamente curtos e normalmente não elevam a temperatura das superfícies (CDT, 2012; SON; YUEN, 1993). Já a condensação intersticial, de mais difícil identificação, ocorre a partir da condução de vapor de água quente (sob maior pressão) do interior da edificação rumo ao exterior dela, gerando umidade na estrutura permeável (CDT, 2012; SON; YUEN, 1993).

Como consequência direta da presença de umidade por condensação tem-se a formação e o crescimento de fungos e microflora bacteriana, o que representa um risco para a vida dos que habitam a edificação ou despendem tempo nela (RYAN, 2002; SON; YUEN, 1993; VEDACIT, 2010). O revestimento pode apresentar características manchas pretas, brancas e verdes; para que a superfície possa ser reparada, é necessário tratamento com fungicidas e/ou remoção do bolor para posterior reparo do elemento construtivo (SON; YUEN, 1993).

\subsection{Umidade de construção}

Durante o processo de construção ou reparo de uma edificação, vários dos materiais empregados valem-se de água no seu processo produtivo, como argamassas e concretos, ou na sua aplicação na obra, como no caso das alvenarias em tijolos (CDT, 2012; HENRIQUES, 1994; RODRIGUES; SOBRINHO JÚNIOR; LIMA, 2016; RODRIGUEZ, 2004). Essa fonte de umidade é, no entanto, costumeiramente ignorada pelos responsáveis pela obra, podendo levá-la a apresentar milhares de litros de água a mais que o projetado (HENRIQUES, 1994).

A incidência de chuva no canteiro de obras ou sobre os materiais de construção acaba por umedecer os componentes da edificação e fazê-los deteriorar com maior facilidade (HENRIQUES, 1994; IOM, 2004; RODRIGUEZ, 2004; WHO, 2009). No entanto, o acelerar dos processos construtivos sem dar às peças tempo suficiente para curar (concreto) ou secar (demais materiais) tem efeito tão negativo quanto fenômenos climáticos (RODRIGUEZ, 2004; SON; YUEN, 1993). 
O processo de secagem dos materiais, porém, tem três partes distintas devido à localização da água na peça. Na primeira fase, que é a mais rápida, ocorre a evaporação da água sobre a superfície do material. Já na segunda e na terceira ocorre a evaporação da água presente, respectivamente, nos poros de maiores dimensões e nos poros de menores dimensões, o que pode demandar anos, já que a água precisa trilhar seu caminho por inúmeros poros até a superfície sob a forma líquida ou gasosa (HENRIQUES, 1994; RODRIGUES; SOBRINHO JÚNIOR; LIMA, 2016). Caso o excesso de água na edificação não seja retirado de alguma forma, pode haver o aparecimento de eflorescências e mofo, além de que a expansão da água na forma de vapor ao evaporar pode causar danos à estrutura da construção (CDT, 2012; RODRIGUEZ, 2004; WHO, 2009).

\subsection{Umidade de precipitação}

Regiões de clima tropical, além de apresentarem temperaturas e umidade relativa do ar elevadas, são caracterizadas pelos intensos períodos chuvosos, que podem causar sérias lesões às construções (FIGUEIREDO; VARUM; COSTA, 2012).

A precipitação, seja em forma de chuva, neve ou granizo, causa maiores danos para o envelope do edifício quando somada do componente vento, o que permite-lhe atingir horizontalmente a edificação (CDT, 2012; HENRIQUES, 1994; KHARSEH et al., 2017; PROSKIW, 2007; RODRIGUES; SOBRINHO JÚNIOR; LIMA, 2016; SON; YUEN, 1993). A chuva, além de agredir paredes e muros com a energia cinética da queda, pode gerar uma cortina de umidade que leva à penetração da água por capilaridade, pelos poros da alvenaria ou pela própria ação da gravidade (HENRIQUES, 1994).

Por sua vez, a neve pode congelar em telhados, criando barreiras de gelo (ice dams). As camadas de neve em contato com as partes aquecidas do telhado derretem e escorrem, através de caminhos para drenagem, até as partes mais externas do telhado, expostas a condições térmicas abaixo de zero, onde congelam aumentando o revestimento em gelo e formando estruturas semelhantes a estalactites (IOM, 2004).

O fato de ser a fonte mais comum de umidade numa edificação (HENRIQUES, 1994; SON; YUEN, 1993) dialoga diretamente com as inúmeras formas de proteção utilizadas pelo ser humano para impermeabilizar suas construções (IOM, 2004), como gravidade, lacunas de ar e materiais impermeáveis (IOM, 2004; LSTIBUREK; CARMODY, 1991). Erros de projeto, tais como descuidos no posicionamento da edificação frente ao clima da região e erros construtivos, como na colocação de janelas e portas e na confecção de pisos, paredes e 
fundações, levam, no entanto, a uma maior frequência de aparição de anomalias sobre a edificação.

\section{MANIFESTAÇÃO E COMBATE À UMIDADE}

\subsection{Terminologia das patologias}

Segundo o CIB W86 (1993), diferentes termos dentro da área de Patologia das Construções podem vir a gerar problemas de compreensão no meio prático-acadêmico devido, principalmente, à semelhança semântica entre terminologias advindas de diversas línguas (CIB W86, 1993). Visto isso, buscou-se traduzir e elencar no Quadro 1 os conceitos mais recorrentes no ramo da construção e outros que encontram paralelo, inclusive, na área da Medicina (SILVA, 2011) para um maior aproveitamento dos dados apresentados na pesquisa. A FIG. 2, por sua vez, indica como a terminologia se relaciona no processo de busca pela patologia construtiva e sua correção.

\begin{tabular}{|c|c|}
\hline Conceito & Significado \\
\hline Anamnese & $\begin{array}{l}\text { Processo que busca relembrar todo o histórico de "doenças" que } \\
\text { afligem a uma edificação, atuando como as primícias de um } \\
\text { diagnóstico }{ }^{[2]} \text {. }\end{array}$ \\
\hline Anomalia & $\begin{array}{l}\text { Indicação de possível defeito, manifestação visual dos problemas } \\
\text { que acometem à construção } \\
{ }^{[1][3]} \text {. }\end{array}$ \\
\hline Dano & $\begin{array}{l}\text { Resultante de defeitos ou anomalias, é indicado na forma de custos } \\
\text { em dinheiro }{ }^{[1]}\end{array}$ \\
\hline Defeito & $\begin{array}{l}\text { Situação onde os elementos de uma construção não executam as } \\
\text { funções para as quais foram criados; deficiência }{ }^{[1]} \text {. }\end{array}$ \\
\hline Diagnóstico & 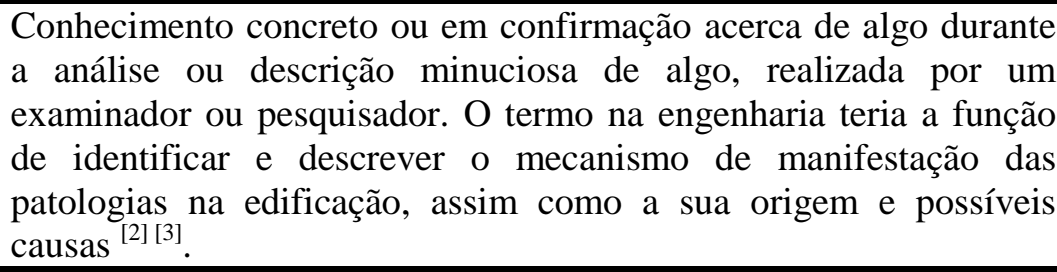 \\
\hline Erro & $\begin{array}{l}\text { Má escolha ou decisão errônea tomada por algum dos indivíduos } \\
\text { relacionados com a obra }{ }^{[1]} \text {. }\end{array}$ \\
\hline Falha & $\begin{array}{l}\text { Findar das capacidades de um item para executar a função ao qual } \\
\text { foi requisitado; falta de desempenho de um elemento }{ }^{[1]} \text {. }\end{array}$ \\
\hline Inspeção & $\begin{array}{l}\text { Coleta de dados para identificação dos fenômenos observados na } \\
\text { construção, podendo ser acompanhada por ensaios para confirmar } \\
\text { as suspeitas do perito }{ }^{[3]} \text {. }\end{array}$ \\
\hline Omissão & $\begin{array}{l}\text { Preterição, esquecimento por parte dos construtores de algo relativo } \\
\text { à construção a ser erguida }{ }^{[1]} \text {. }\end{array}$ \\
\hline Perda & $\begin{array}{l}\text { Resultado direto dos defeitos e anomalias apresentados na } \\
\text { construção, expresso em lesões e vidas perdidas }{ }^{[1]} \text {. }\end{array}$ \\
\hline
\end{tabular}




\begin{tabular}{|c|c|}
\hline Profilaxia & $\begin{array}{l}\text { É a utilização de meios e recursos com o intuito de prevenir e evitar } \\
\text { doenças. No campo da construção civil, por sua vez, significa a } \\
\text { aplicação de métodos e procedimentos que evitem as "doenças" que } \\
\text { acometam o edifício, bem como suas propagações }{ }^{[2]} \text {. }\end{array}$ \\
\hline Prognóstico & $\begin{array}{l}\text { Juízo médico, baseado no diagnóstico e nas possibilidades de } \\
\text { tratamento, acerca da duração e do desenvolvimento de uma } \\
\text { doença, ou ainda predição, agouro. Na construção civil, traça a } \\
\text { provável evolução de um processo e seu resultado no futuro caso } \\
\text { não sejam aplicadas as medidas corretivas para sua eliminação }{ }^{[2][3]} \text {. }\end{array}$ \\
\hline Terapia & $\begin{array}{l}\text { Alude ao tratamento indicado a uma dada doença pela medicina } \\
\text { tradicional, ou por meio de terapia alternativa. No campo da } \\
\text { engenharia civil, seria uma recomendação de ação imediata ou não } \\
\text { a ser realizada com relação à situação da edificação, como reparos, } \\
\text { reforços etc. }{ }^{[2][3]} \text {. }\end{array}$ \\
\hline
\end{tabular}

Quadro 1 - Terminologias utilizadas nas patologias da Construção Civil Conclusão. Fontes: ${ }^{[1]}$ CIB W86 (1993); ${ }^{[2]}$ Silva (2011); ${ }^{[3]}$ Tutikian e Pacheco (2013).

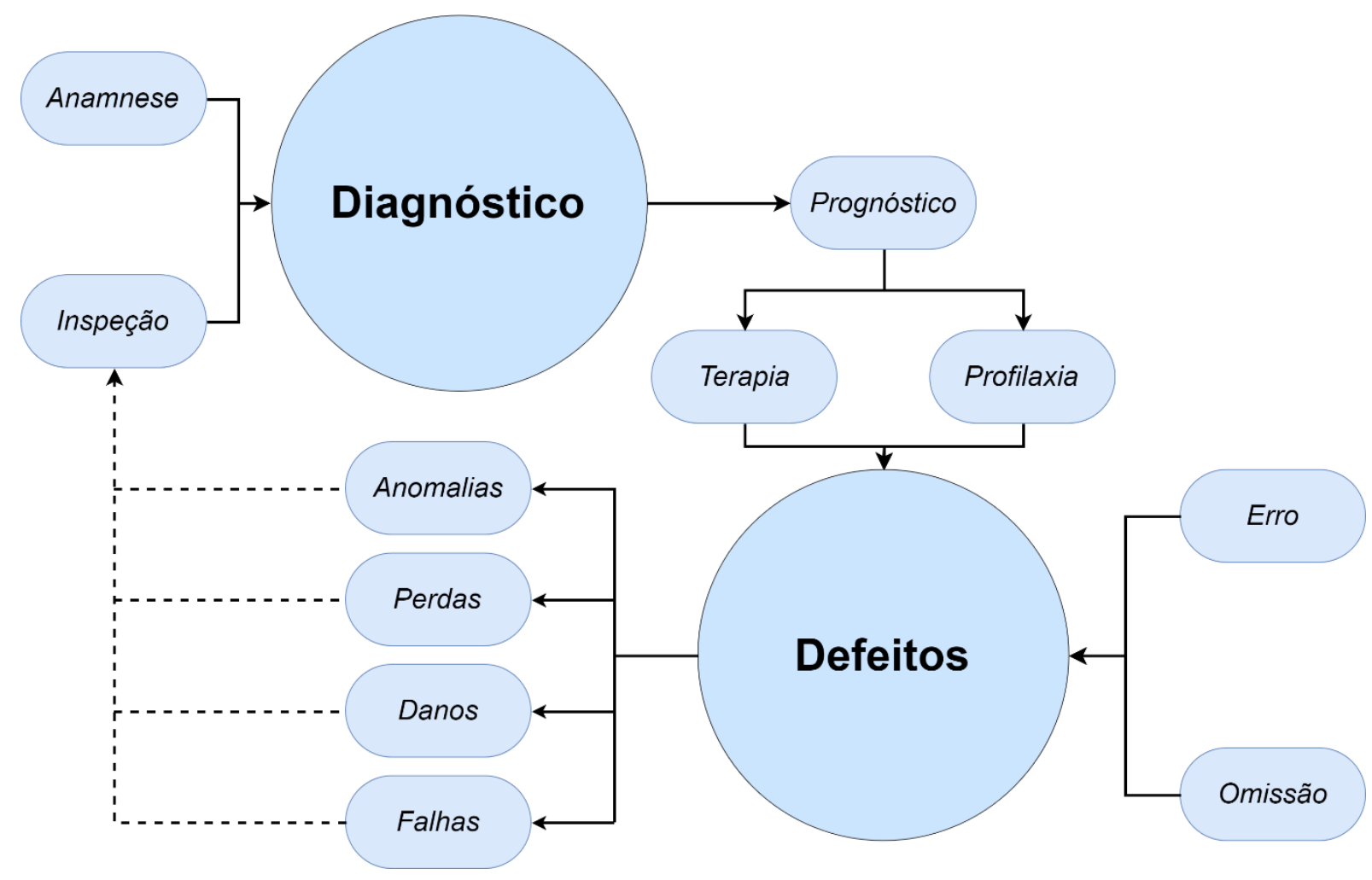

Figura 2 - Cadeia de eventos de manifestação e tratamento de patologias construtivas Fonte: Dos autores.

\subsection{Sintomas de patologias provocadas pela umidade}

O desempenho de uma edificação advém da forma pela qual ela reage às condições externas às quais é exposta, tendendo a um equilíbrio dinâmico. No entanto, a forma como um 
edifício se comporta frente à ação externa varia devido a elementos do processo construtivo, como desleixos na projeção ou na construção, ou até mesmo à negligência no uso da estrutura (RODRIGUES; SOBRINHO JÚNIOR; LIMA, 2016; TUTIKIAN; PACHECO, 2013).

Tais fatores colaboram para o surgimento nas edificações de anomalias e defeitos que, se não corrigidos, podem evoluir para graus patológicos mais altos. O Quadro 2, a seguir, apresenta os indícios visíveis das patologias oriundas da umidade e as condições e causas que incitam suas manifestações em edificações.

\begin{tabular}{|c|c|c|}
\hline $\begin{array}{c}\text { Tipo de } \\
\text { Umidade }\end{array}$ & Indícios e anomalias & Causas ou condições estimulantes \\
\hline $\begin{array}{l}\text { Umidade } \\
\text { acidental }\end{array}$ & $\begin{array}{l}\text { manchas de umidade e zonas } \\
\text { úmidas nas cercanias de } \\
\text { tubulações com defeito }{ }^{[4]} \text {; }\end{array}$ & $\begin{array}{l}\text { rotura de tubulações internas, como em cozinhas e } \\
\text { banheiros }{ }^{[4]} \text {; } \\
\text { design inadequado }{ }^{[1]} ; \\
\text { falta de manutenção }{ }^{[1]} \text {; }\end{array}$ \\
\hline $\begin{array}{c}\text { Umidade } \\
\text { ascensional }\end{array}$ & $\begin{array}{l}\text { manchas úmidas de altura } \\
\text { variável em paredes próximas } \\
\text { ao solo }{ }^{[3]} \text {; } \\
\text { bolores, vegetação parasitária, } \\
\text { eflorescências, } \\
\text { criptoflorescências }{ }^{[3]} \text {; }\end{array}$ & $\begin{array}{l}\text { alto nível de lençol freático }{ }^{[2]} ; \\
\text { presença de sais }{ }^{[2]} ; \\
\text { drenagem ineficaz }{ }^{[2]} ; \\
\text { fundações executadas com impermeabilização } \\
\text { ineficaz }{ }^{[2]} \text {; } \\
\text { argamassa utilizada na alvenaria }^{[2]} ; \\
\end{array}$ \\
\hline $\begin{array}{l}\text { Umidade de } \\
\text { condensação }\end{array}$ & $\begin{array}{l}\text { manchas de umidade, fungos e } \\
\text { microflora bacteriana no } \\
\text { interior de paredes }{ }^{[3]}[5] \text {; } \\
\text { apodrecimento de matéria } \\
\text { orgânica [3]; zonas de } \\
\text { umedecimento no interior das } \\
\text { paredes externas }{ }^{[3]} \text {; }\end{array}$ & $\begin{array}{l}\text { isolamento térmico insuficiente das paredes } \\
\text { exteriores }{ }^{[3]} \text {; } \\
\text { condições de ventilação deficientes ou uso errôneo } \\
\text { destas }{ }^{[2][3]} \text {; } \\
\text { altas temperaturas e alta umidade relativa do ar }{ }^{[1]} \\
{ }^{[6]} \text {; }\end{array}$ \\
\hline $\begin{array}{l}\text { Umidade da } \\
\text { construção }\end{array}$ & $\begin{array}{l}\text { zonas de umedecimento em } \\
\text { paredes internas e externas } \\
\text { eflorescências e mofo } \\
{ }^{[1][5][7]}\end{array}$ & $\begin{array}{l}\text { incidência de chuva sobre o canteiro de obras e } \\
\text { sobre os materiais de construçãõo }{ }^{[3][4]} \text {; } \\
\text { aceleração do processo construtivo, não dando } \\
\text { tempo para a secagem total dos materiais }{ }^{[5]}\left[{ }^{[6]} \text {; }\right.\end{array}$ \\
\hline $\begin{array}{l}\text { Umidade de } \\
\text { precipitação }\end{array}$ & $\begin{array}{l}\text { manchas de umidade na parte } \\
\text { interna das paredes expostas a } \\
\text { chuvas }{ }^{[3]} \text {; } \\
\text { bolores e eflorescências }{ }^{[3]} \text {. }\end{array}$ & $\begin{array}{l}\text { reboco de baixa qualidade }{ }^{[3]} \text {; } \\
\text { detalhes mal projetados ou mal executados }{ }^{[2]} \text {; } \\
\text { muro duplo (juntas abertas ou mal preenchidas de } \\
\text { material impermeabilizante) }{ }^{[2]} \text {; } \\
\text { rotura de tubos de queda de águas pluviais }{ }^{[3]} \text {. }\end{array}$ \\
\hline
\end{tabular}

Quadro 2 - Manifestação patológica da umidade em construções

Fonte: ${ }^{[1]}$ CDT (2012). ${ }^{[2]}$ CIB W086 (1993). ${ }^{[3]}$ Henriques (1994). ${ }^{[4]}$ IOM (2004). ${ }^{[5]}$ Rodrigues (2004). ${ }^{[6]}$ SON; Yuen (1993). ${ }^{[7]}$ WHO (2009).

\subsection{Prevenção e tratamento de patologias oriundas da ação da água}

Ao projetar uma edificação deve ser considerada a realização de projetos de impermeabilização e proteção contra a umidade. Se bem executados, os custos relativos à impermeabilização em uma obra não ultrapassam $2 \%$ de seu valor total (IBI, 2017). Todavia, a vasta quantidade de falhas relatadas em projetos de impermeabilização (RODRIGUES; ForSci.: r. cient. IFMG campus Formiga, Formiga, v. 6, n. 3, e00476, jul./dez. 2018. 
SOBRINHO JÚNIOR; LIMA, 2016) expõe a despreocupação prévia com possíveis falhas futuras.

O processo de tratamento de uma patologia construtiva, por sua vez, é relativamente mais oneroso, como apontado pelo Projeto de Pesquisa e Organização Normativo da Índia Research Design and Standards Organization (RDSO) (RDSO, 2015), devendo ser considerados fatores como o tipo de construção, os recursos a serem disponibilizados para tal e os resultados objetivados, pois para uma mesma anomalia pode haver mais de uma solução (HENRIQUES, 1994).

Neste contexto, elencou-se no Quadro 3 um conjunto sucinto de ações a serem realizadas durante a execução da obra com o intuito de minimizar a ação da umidade sobre a edificação. O Quadro 4, por sua vez, lista de forma concisa possíveis soluções para cada um dos cinco tipos de umidade trabalhados, estando separadas em "Eliminação e ocultação de anomalias", que indicará soluções de cunho temporário e de menor custo a curto-prazo, e "Remoção das causas de umidade", que apresentam intervenções mais eficazes, porém de maior custo.

\begin{tabular}{|c|c|}
\hline $\begin{array}{c}\text { Tipo de } \\
\text { Umidade }\end{array}$ & Prevenção na execução do projeto \\
\hline $\begin{array}{l}\text { Umidade } \\
\text { acidental }\end{array}$ & $\begin{array}{l}\text { Correta execução dos sistemas de canalização interna }{ }^{[4]}\left[{ }^{[5]} ;\right. \\
\text { Execução de rebaixos em ralos para evitar acúmulo de água }{ }^{[4]}\end{array}$ \\
\hline $\begin{array}{c}\text { Umidade } \\
\text { ascensional }\end{array}$ & 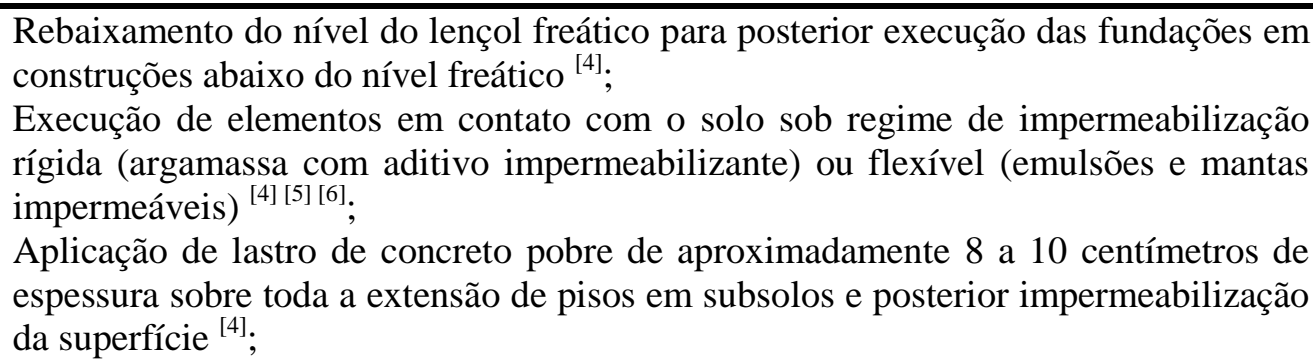 \\
\hline $\begin{array}{l}\text { Umidade de } \\
\text { condensação }\end{array}$ & Aumento da inércia térmica da alvenaria através da circulação de ar ${ }^{[2]}[5]$; \\
\hline $\begin{array}{l}\text { Umidade da } \\
\text { construção }\end{array}$ & $\begin{array}{l}\text { Aumento da inércia térmica entre as paredes através de ventilação dos cômodos }{ }^{[1]} \\
\text { [5]; } \\
\text { Atenção à dosagem e traço de argamassas e concretos }{ }^{[4]}[5] \text {; } \\
\text { Verificação com relação à proteção do canteiro de obra quanto à infiltração de água } \\
\text { de chuva durante a execução do serviço }{ }^{[4]} \text {; }\end{array}$ \\
\hline $\begin{array}{l}\text { Umidade de } \\
\text { precipitação }\end{array}$ & $\begin{array}{l}\text { Execução de sócolo externo em alvenarias junto a calçadas de cerca de } 60 \\
\text { centímetros de altura, protegendo a parede de respingos e água empoçada }{ }^{[4]} \text {; } \\
\text { Aplicação de pinturas à base de silicone, verniz acrílico ou verniz poliuretânico } \\
\text { sobre fachadas }{ }^{[4][5]} \text {; } \\
\text { Realização de sistemas flexíveis de impermeabilização em lajes de cobertura e pisos } \\
\text { (emulsões e mantas cimentícias) }{ }^{[3][4][5][6]} \text {; }\end{array}$ \\
\hline
\end{tabular}

Quadro 3 - Proteção contra umidade na execução da obra

Fonte: ${ }^{[1]}$ Henriques (1994), ${ }^{[2]}$ Kluppel e Santana (2000), ${ }^{[3]}$ RDSO (2015), ${ }^{[4]}$ Ribeiro, Soares e Santos (2017), ${ }^{[4]}$ Ripper (1984) e ${ }^{[5]}$ Vedacit (2010). 


\begin{tabular}{|c|c|c|}
\hline $\begin{array}{l}\text { Tipo de } \\
\text { Umidade }\end{array}$ & $\begin{array}{c}\text { Eliminação e ocultação de } \\
\text { anomalias }\end{array}$ & Remoção das causas de umidade \\
\hline $\begin{array}{l}\text { Umidade } \\
\text { acidental }\end{array}$ & $\begin{array}{l}\text { Adoção de forros impermeáveis } \\
\text { em paredes afetadas }{ }^{[2]} \text {; }\end{array}$ & Substituição ou emenda de tubulações ${ }^{[3][4]}$; \\
\hline $\begin{array}{l}\text { Umidade } \\
\text { ascensional }\end{array}$ & $\begin{array}{l}\text { Execução de nova parede de } \\
\text { pequena espessura e de materiais } \\
\text { autoportantes, de base } \\
\text { impermeabilizada, afastada da } \\
\text { parede por onde ventilar-se-á para } \\
\text { o exterior }{ }^{[1]}[2] ; \\
\text { Aplicação de recobrimentos } \\
\text { impermeáveis sobre as paredes } \\
\text { afetadas após remoção do } \\
\text { revestimento úmido }{ }^{[2][6] ;}\end{array}$ & 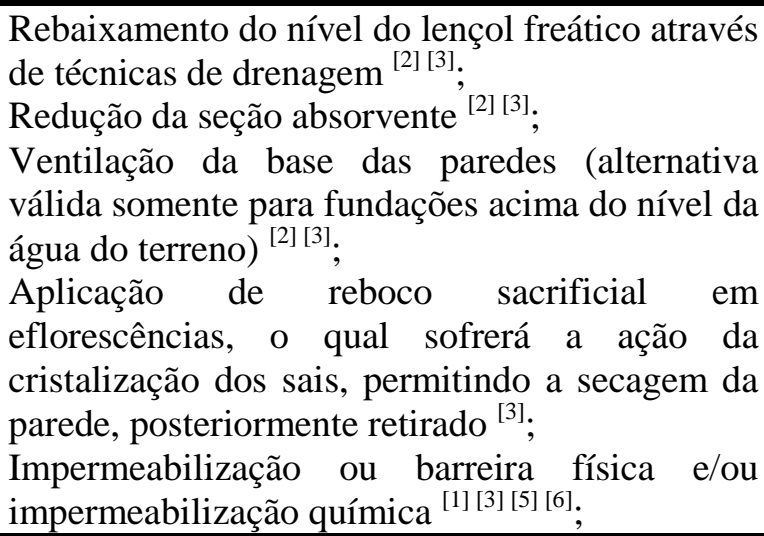 \\
\hline $\begin{array}{l}\text { Umidade de } \\
\text { condensação }\end{array}$ & $\begin{array}{l}\text { Execução de nova parede de } \\
\text { pequena espessura e de materiais } \\
\text { autoportantes, de base } \\
\text { impermeabilizada, afastada alguns } \\
\text { centímetros da parede (ventilação } \\
\text { necessária somente caso a parede } \\
\text { esteja úmida) }{ }^{[2]} \text {; } \\
\text { Emprego de revestimentos } \\
\text { impermeáveis sobre as paredes } \\
\text { afetadas após remoção do } \\
\text { revestimento úmido }{ }^{[2][6] ;}\end{array}$ & $\begin{array}{l}\text { Aumento da inércia térmica entre as paredes } \\
\text { (aplicação de isolamento térmico, aumento da } \\
\text { ventilação nos cômodos ou aumento da } \\
\text { temperatura superficial das paredes) }{ }^{[2]}[3] \text {; } \\
\text { Para casos de ataque de microrganismos, é } \\
\text { válida a escovação, imunização e posterior } \\
\text { execuçãa de novo acabamento sobre a alvenaria } \\
\text { afetada }{ }^{[2]}{ }^{[3]} \text {; }\end{array}$ \\
\hline $\begin{array}{l}\text { Umidade da } \\
\text { construçãao }\end{array}$ & $\begin{array}{l}\text { Execução de nova parede de } \\
\text { pequena espessura e de materiais } \\
\text { autoportantes, de rase base } \\
\text { impermeabilizada, afastada da } \\
\text { parede por onde ventilar-se-á para } \\
\text { o exterior }{ }^{[2][3]} \text {; }\end{array}$ & $\begin{array}{l}\text { Aumento da inércia térmica entre as paredes } \\
\text { através de ventilação dos cômodos, aumento da } \\
\text { temperatura superficial das paredes ou } \\
\text { diminuição da umidade relativa do ar a partir de } \\
\text { desumidificadores }{ }^{[2][3]} \text {; }\end{array}$ \\
\hline $\begin{array}{l}\text { Umidade de } \\
\text { precipitação }\end{array}$ & $\begin{array}{l}\text { Remoção do revestimento } \\
\text { degradado e execução de nova } \\
\text { superfície impermeabilizada } \\
\text { [5]; } \\
\text { Aplicação de hidrófugo nas } \\
\text { paredes exteriores (impedindo a } \\
\text { penetração da água líquida, mas } \\
\text { permitindo a movimentação de } \\
\text { sua forma gasosa) }{ }^{[2]} ; \\
\text { Proteção com pintura } \\
\text { impermeável }{ }^{[5] ;}\end{array}$ & $\begin{array}{l}\text { Verificação e correção de infiltrações em beirais, } \\
\text { platibandas e panos de cobertura danificados }{ }^{[3]} \text {; } \\
\text { Retirada do reboco umedecido, } \\
\text { impermeabilização das juntas entre os materiais } \\
\text { e reaplicação de reboco bem executado nas } \\
\text { paredes }{ }^{[3]} \text {; } \\
\text { Proteção com pintura impermeável }{ }^{[5]} \text {; }\end{array}$ \\
\hline
\end{tabular}

Quadro 4 - Intervenções de reparo de anomalias provocadas pela umidade

Fonte: ${ }^{[1]}$ Freitas e Guimarães (2014). ${ }^{[2]}$ Henriques (1994). ${ }^{[3]}$ Klupper e Santana (2000). $\quad{ }^{[4]}$ Paz et al. (2016). ${ }^{[5]}$ Ribeiro, Soares e Santos (2017). ${ }^{[6]}$ Ripper (1984). 


\title{
6 CONCLUSÃO
}

Tomando como premissa as informações apresentadas acerca das formas de manifestação da umidade em construções, poder-se-ia, ainda, separá-las em dois grandes blocos quanto a sua origem, a qual pode ser devido a fatores antrópicos, como uso da habitação e desleixos na execução e na projeção da obra, ou a fatores naturais, como questões climatéricas e águas subterrâneas.

Logo, para impedir a degradação por intempéries e amenizar os danos oriundos da própria utilização da edificação, é necessário ressaltar a relevância do projeto de impermeabilização em construções, visto a umidade ser capaz de causar tanto lesões à estrutura da edificação quanto consequências negativas à saúde dos que usufruem do imóvel.

A água, em suas características físico-químicas tão necessárias à vida na Terra, acaba por atuar como o maior agente degradante no âmbito da construção civil, devendo ser combatida desde as primícias da construção. Para tal, dever-se-ia atentar para a elaboração de um projeto de impermeabilização eficaz que compusesse o conjunto mínimo de projetos necessários para a execução de um empreendimento.

Além da preocupação com o combate à umidade desde a concepção do projeto, é fundamental que o manual do proprietário, documento a ser entregue ao proprietário/usuário com orientações acerca dos cuidados a serem tomados com a edificação, contemple de forma satisfatória a temática da umidade, de forma a evitar a manifestação de anomalias decorrentes da ação da água e a minimizar os gastos posteriores com tratamento.

Já para os casos em que os sintomas anômalos da umidade estão em franca ascensão, é válido despender a devida atenção ao processo de diagnóstico, dado que a umidade pode se manifestar por múltiplas formas simultaneamente, o que dificulta a tomada de decisões quanto ao tratamento mais indicado. O prognóstico, por sua vez, deverá trazer, como possíveis soluções, a eliminação e/ou ocultação das anomalias e a remoção das causas de umidade, devendo ser ponderado junto ao proprietário as questões relativas ao custo e à eficácia de cada tipo de tratamento.

\section{MOISTURE IN BUILDINGS: UNDERSTAND TO COMBAT}

\begin{abstract}
Water is one of the major problems within the scope of Civil Engineering studies, since it originates about $80 \%$ of all constructive pathologies, it can still cause damage to the health of


the building occupants. Even though it is present in both: the external environment (in the form of rain and groundwater) and in the internal environment of the dwelling (in the act of cooking and bathing, for example), in many constructions the waterproofing project is neglected, then the moisture manifest in a variety of ways. In this context, it was sought to classify water as its manifestation form through the data exposed by classic and contemporary authors, as well as to enumerate indications of its deteriorating action, forms of treatment and preventive measures to be taken against moisture. The purpose of this article is that the information presented can help identify and repair moisture-related pathologies and highlight the importance of waterproofing projects, leading them to be included in the set of minimum projects required to execution of a work.

Keywords: Moisture. Buildings Pathology. Buildings maintenance. Waterproofing.

\section{REFERÊNCIAS}

AGYEKUM, K. et al. Preliminary assessment of dampness in walls of residential buildings in four climatic zones in Ghana. Journal of Sustainable Development, v. 6, n. 9, p. 51-61, Aug. 2013.

ANILLA, P. J. et al. Extent of moisture and mould damage in structures of public buildings. Case Studies in Construction Materials, v. 6, p. 103-108, 2017.

CIB WORKING COMMISSION W86. Building pathology: a state-of-the-art report. Rotterdam, The Netherlands: CIB, 1993.

CORPORACIÓN DE DESARROLLO (CDT). Húmedad por condensación en viviendas. 2. ed. Santiago de Chile: Trama Impresores, 2012.

DEMO, M. Study on the effect of moisture in the building. Interdisplinary Journal of Research and Development, v. 4, n. 2, p. 115-120, 2017.

FIGUEIREDO, M. G. de; VARUM, H.; COSTA, A. Aspectos da arquitetura civil edificada no século XIX, em São Luís do Maranhão, Brasil. Conservar Patrimônio, n. 15, p. 43-68, 2012.

FRANZONI, E.; BANDINI, S.; GRAZIANI, G. Rising moisture, salts and electrokinetic effects in ancient masonries: from laboratory testing to on-site monitoring. Journal of Cultural Heritage, v. 15, n. 2, p 112-120, 2014.

FREITAS, V. P. de. (Ed.). A State-of-the-Art Report on Building Pathology. Portugal: CIB - W086 Building Pathology, 2013.

FREITAS, V. P., GUIMARÃES, A. S. Tratamento da humidade ascensional no património histórico. Revista ALCONPAT, Mérida, v. 4, n. 1, p. 1-13, jan./abr. 2014. 
HENRIQUES, F. M. A. Humidade em paredes. 4. ed. Lisboa, Portugal: Laboratório Nacional de Engenharia Civil, 1994.

INSTITUTE OF MEDICINE (IOM). Damp indoor spaces and health. Washington, D. C.: The National Academies Press, 2004.

INSTITUTO BRASILEIRO DE IMPERMEABILIZAÇÃO (IBI). O que é impermeabilização? São Paulo, 2017. Disponível em: <http://ibibrasil.org.br/2017/10/17/oque-e-impermeabilizacao/>. Acesso em: 16 fev. 2018.

KHARSEH, M. et al. Humid wall: review on causes and solutions. In: WORLD SUSTAINABLE BUILT ENVIRONMENT CONFERENCE, 2017, Hong Kong. Conference Proceedings... Sweden: Chalmers University of Technology, 2017. p. 675-681.

KLÜPPEL, G. P.; SANTANA, M. C. de. Manual de conservação preventiva para edificações. Brasília: Programa Monumenta, 2000.

LICHTENSTEIN, N. B. Patologias das construções: procedimento para diagnóstico e recuperação. Boletim Técnico da Escola Politécnica da USP, São Paulo, BT 06/86, 1986.

LSTIBUREK, J.; CARMODY, J. Moisture control handbook: new, low-rise, residential construction. United States: The Department of Energy (DOE), 1991.

PAZ, L. A. F. da et al. Levantamento de patologias causadas por umidade em uma edificação na cidade de Palmas - TO. Revista Eletrônica em Gestão, Educação e Tecnologia Ambiental, Santa Maria, v. 20, n. 1, p. 174-180, 2016.

PROSKIW, G. Case studies of moisture problems in buildings. In: THERMAL PERFORMANCE OF EXTERIOR ENVELOPES OF WHOLE BUILDINGS, 10., 2007, Clearwater Beach, Florida. CONFERENCE PROCEEDING... [Atlanta, GA]: ASHRAE, 2007.

RESEARCH DESIGN AND STANDARDS ORGANIZATION (RDSO). Guidelines on Waterproofing in New/Old construction. Lucknow, India: Government of India. Ministry of Railways, 2015.

RIBEIRO, D. J.; SOARES, W. C.; SANTOS, S. X. Patologias causadas pela umidade: estudo de caso em uma edificação residencial no município de Nova União/MG. Revista CONSTRUINDO, Belo Horizonte, v. 9, Ed. Esp. de Patologia, p. 72 - 92, 2017.

RIPPER, E. Como evitar erros na construção. São Paulo: Pini, 1984.

RODRIGUES, R. M.; SOBRINHO JÚNIOR, A. da S.; LIMA, E. E. P. Erros diagnósticos e soluções de impermeabilização na construção civil. InterScientia, v. 4, n. 2, p. 19-33, 2016. 
RODRIGUEZ, V. (Coord.). Manual de patología de la edificación. Tomo 3. Madrid, Espanha: Universidad Politécnica, 2004.

RYAN, V. Condensation in dwellings. Journal of Environmental Health Research Methods, v. 1, n. 1, p. 25-30, 2002.

SILVA, F. B. Patologia das construções: uma especialidade na engenharia civil. Téchne, São Paulo, v. 19, n. 174, p. 72-77, set. 2011.

SON, L. H.; YUEN, G. C. S. Building maintenance technology. Houndmills, Basingstoke, Hampshire: MacMillan Press, 1993.

STRAUBE, J. F. Moisture in buildings. ASHRAE Journal, v. 44, n.1, p. 15-19, Jan., 2002.

TUTIKIAN, B.; PACHECO, M. Boletín Técnico 1: inspección, diagnóstico y prognóstico en la construcción civil. Mérida, México: Asociación Latinoamericana de Control de Calidad, Patología y Recuperación de la Construcción (ALCONPAT), 2013.

VEDACIT. Manual técnico: impermeabilização de estruturas. 6. ed. São Paulo: Vedacit Impermeabilizantes, 2010.

WORLD HEALTH ORGANIZATION (WHO). WHO guidelines for indoor air quality: dampness and mould. Copenhagen, Denmark, 2009.

\section{DADOS DOS AUTORES}

\section{Yuri Mariano Carvalho}

E-mail: yuri.mariano@engenharia.ufjf.br

Currículo Lattes: http://lattes.cnpq.br/1982095463163692

Graduando em Engenharia Civil na Universidade Federal de Juiz de Fora (UFJF).

\section{Vivian Gemiliano Pinto}

E-mail: vivian.pinto@ifsudestemg.edu.br

Currículo Lattes: http://lattes.cnpq.br/5038877050043879

Doutora em Ecologia pela Universidade Federal de Juiz de Fora (UFJF). Mestra em Saneamento, Meio Ambiente e Recursos Hídricos pela Universidade Federal de Minas Gerais (UFMG) (2006). Graduada em Engenharia Civil pela Universidade Federal de Juiz de Fora (UFJF) (1997) e professora do Instituto Federal de Educação Ciência e Tecnologia do Sudeste de Minas Gerais - Campus Juiz de Fora. 